\title{
VAMOS A CONTAR MENTIRAS, TRALARÁ..., O DE LÍMITES A LOS DICHOS DE LOS ABOGADOS
}

\author{
Rodrigo Coloma Correa*
}

\author{
Abora que vamos despacio, (bis) \\ vamos a contar mentiras, tralará, (bis) \\ Vamos a contar mentiras. \\ Por el mar corren las liebres, (bis) \\ por el monte las sardinas, tralará, (bis) \\ por el monte las sardinas...
}

(Canción infantil)

\section{RESUMEN}

En el presente trabajo se exploran los alcances que la obligación de decir la verdad tendría respecto a los discursos presentados por los abogados ante los tribunales de justicia. Luego de realizar precisiones acerca de los juegos de lenguaje en los que corresponde participar a los abogados, se sugiere que su obligación de decir la verdad es bastante más débil que la imperante en otros contextos en los que se cuenta con pretensiones eminentemente teóricas. En este sentido, si bien es cierto que la obligación de decir la verdad opera con cierta fuerza respecto de la producción de bechos primarios, ella es casi inexistente en relación a la construcción de historias para efectos de conectar a éstos con la condición de aplicación de las normas jurídicas.

\section{ABOGADOS - DEFENSA DE CLIENTES -VERDAD}

\section{Let's go to tell lies... or the limits on the attorneys' statements}

\begin{abstract}
This paper explores the limits that the duty to tell the truth has in respect of the arguments presented by attorneys before the courts of justice. After making some comments on language games that attorneys must play, it is suggested that their obligation to tell the truth is quite weaker than the obligation existing in other contexts in which claims are eminently theoretical. In this regard, although it is true that the obligation to tell the truth is somewhat forceful in regard to the production of primary facts, it is virtually non-existent in the construction of stories for the purpose of connecting them to the application of the rules of law.
\end{abstract}

\section{ATTORNEYS - CLIENT DEFENSE - TRUTH}

* Abogado. Doctor en Derecho. Profesor de la Universidad Alberto Hurtado (Cienfuegos 41, Santiago, rcoloma@uahurtado.cl)y de la Universidad Católica de Temuco (Manuel Montt 56, Temuco, rcoloma@uct.cl). Trabajo recibido el 29 de septiembre de 2006 y aceptado para su publicación por el Comité Editorial el 6 de noviembre de 2006. 
prueba reglada -desde hace tiempo en franca retirada ${ }^{24}$ - que aspiraban no sólo a poner barreras a la información potencialmente admisible, sino también a la manera en que ella debía valorarse.

Sobre los jueces se ciernen expectativas en orden a que lleguen a seleccionar historias que satisfagan la posibilidad de ser conectadas con otras esferas de nuestras vidas. ${ }^{25}$ Las mejores historias serán susceptibles de anclarse en una realidad entendida como no determinada únicamente por las palabras. ${ }^{26}$ Esto lleva a que las decisiones puedan escrutarse desde distintos puntos de vista, los cuales - por cierto- no se limitarán a lo ordenado en las reglas del procedimiento, sino que apelarán, por ejemplo, a criterios externos tales como la coherencia, simplicidad y precisión. ${ }^{27}$ No tener en cuenta esto lleva a un fuerte efecto de desmoralización en las personas que impacta en un mayor nivel de incumplimiento de las decisiones, por la ausencia de sentido. ${ }^{28}$ Sin embargo -como ha sido dicho- tales expectativas son más bajas que las usuales en el ámbito científico, aunque, en ocasiones, superiores a las que operan en otras esferas de nuestras vidas, sobre todo, si el impacto que pudiere tener un error no resultare dramático. Una señal en ese sentido puede verse en los estándares de prueba determinados en los sistemas jurídicos, en las reglas sobre carga de la prueba y en el carácter definitivo de las decisiones. Operar con estándares de prueba tales como beyond reasonable doubt $\mathrm{u}$ on a balance of probabilities ${ }^{29}$ constituye una clara muestra de que, si bien el soporte empírico de los discursos no puede ser muy débil, no es necesaria la certeza para su aceptación (lo que, por lo demás, se produce en toda disciplina para la cual sea relevante tratar de aprehender la realidad). Por su parte, las reglas sobre cargas de la prueba, vinculadas estrechamente con el principio de inexcusabilidad, son una muestra palmaria que muchas veces no estamos en condiciones de sostener que algo ha sucedido, como tampoco de sostener que algo no ha sucedido. ${ }^{30}$ Esta situación lleva a que sencillamente se actúe como si algo bubiere sucedido o bien como

${ }^{24}$ Aun cuando en nuestro sistema jurídico queden vestigios, como es el caso del código de procedimiento civil.

${ }^{25}$ Cfr. Wittgenstein. L. "Sobre la certeza”. Gedisa, Barcelona, 2000 (2a reimpresión). Compilado por Anscombe G. E. M. y von Wright, G. H., edición bilingüe, p. 42c.

${ }^{26}$ Cfr. Nagel, Th. "La última palabra”. Gedisa, Barcelona, 2000, pp. 49-63.

${ }^{27}$ Cfr. Kuhn, Th. "Objetividad, juicios de valor y elección de teoría”, en Id. La tensión esencial. Estudios selectos sobre la tradición y el cambio en el ámbito de la ciencia. Fondo de Cultura Económica, Madrid, 1993 (2 reimp. en España de la $1^{\text {a }}$ ed.), pp. 345-346.

${ }^{28}$ Cfr. Tyler, T. "Why people obey the Law”. Yale University Press, New Have-London, 1990, p. 107.

${ }^{29}$ La idea de los estándares de prueba se encuentra mucho más asimilada en el ámbito del common law, tanto es así que en nuestra lengua no hay una terminología asentada para referirse a las exigencias en los casos civiles.

${ }^{30}$ Para estos efectos los enunciados 'no creer $p$ ' y 'creer no $p$ ', no resultan intercambiables. Con el primero de ellos sólo se quiere señalar que no se cree $p$, no diciéndose nada acerca de 'no $p$ ', proposición que también podría no creerse; en cambio, en el segundo caso, además de no creer $p$, el sujeto cree 'no $p$ '. Siguiendo a Searle podría señalarse que 'no creo p' es una negación ilocucionaria, esto es, una negativa de que creo $p$; en cambio, 'creo no p' es una negación proposicional, esto es, una negativa de $p$. SEARLE, J. “Actos de habla”. 5a ed. Cátedra, Madrid, 2001, p. 41. 


\section{Algunas precisiones sobre el lenguaje}

un cuando raramente llegan a ser explicitadas, es indudable que al participar en
cualquier evento comunicativo lo hacemos sometiéndonos a ciertas reglas -usual-
mente complejas y borrosas- de las cuales dependerá el éxito o fracaso de nuestros discursos o textos. Tales reglas, como fácilmente podrá ser advertido, diferirán dependiendo del contexto en que el hablante se esté desenvolviendo, como también de las finalidades que éste se haya propuesto al realizar un determinado acto de habla. ${ }^{1}$ La heterogeneidad de tales reglas -que varían significativamente tanto en el tiempo como en el espacio- lleva, entonces, a que para la cabal comprensión de palabras, oraciones y gestos resulte esencial tener en cuenta el contexto comunicativo en que éstos se desarrollan. Ello, por cierto, no tiene nada de extraordinario ya que el lenguaje es un producto de la convención, y como tal, la manera en que sea aconsejable utilizarlo dependerá de las formas que se encuentren asentadas en una comunidad lingüística que se entiende como relevante.

Lo recién expresado trae consigo que, para efectos de evaluar el éxito o fracaso de un acto de habla, sea preciso tener presente que a través del lenguaje se pueden llevar a cabo variadas funciones, tales como informar, motivar, sorprender, enfurecer, halagar, engañar, divertirse, confundir, etc. ${ }^{2}$ Dicho de otra forma, el lenguaje cuenta con una dimensión semántica que tiene que ver con los significados que son atribuidos a los símbolos a través de los cuales éste se encuentra construido, como también, con una dimensión pragmática que tiene que ver con las funciones que a ellos le son asignadas. J. L. Austin, en su libro Cómo hacer cosas con palabras, representó acertadamente tales características al proponer una distinción que ha sido frecuentemente utilizada en las décadas que han seguido a su publicación. El filósofo oxoniense señalaba que al analizar cualquier acto de habla resultan relevantes los posibles significados de aquello que ha sido dicho (locución); los efectos que el hablante pretende provocar mediante sus actos de habla (ilocución); y también las creencias o actitudes que efectivamente se producen en el auditorio como consecuencia del acto comunicativo (perlocución). ${ }^{3}$

Así, por ejemplo, a partir del enunciado: “¡enciende la luz!” que X dirige a Y se puede realizar la siguiente distinción:

Locución. X ha dicho a Y: ¡Aprieta la tecla del interruptor que regula el paso de la energía eléctrica hacia la ampolleta montada en la lámpara! ${ }^{4}$

${ }^{1}$ Decir - por ejemplo- 'Buenos días' puede ser una forma acertada para iniciar una conversación entre hispanoparlantes, e inapropiada si a quien el hablante se dirige ignora la lengua española. Asimismo, decir 'Lo siento' será una manera apta para dirigirnos a quien acaba de enviudar, y desafortunada, para formularla a quien contraerá matrimonio y que no está de humor para escuchar bromas pesadas.

${ }^{2}$ Cfr. Carrió, G. "Lenguaje, interpretación y desacuerdos en el terreno del derecho" /en/ Id. Notas sobre derecho y lenguaje. $4^{\mathrm{a}}$ ed., Abeledo-Perrot, Buenos Aires, 1990, p. 38-39.

3 Austin, J. L. "Palabras y acciones. Cómo hacer cosas con palabras", 1ª ed. (Compilación de J. O. Ursom) Paidós, Buenos Aires, 1971, p. 153.

${ }^{4}$ Esta reconstrucción del enunciado ¡enciende la luz!, presupone la regla técnica: "apretar la tecla del interruptor es condición necesaria para que se encienda la luz". 
Ilocución. X está tratando de influir en Y para que lleve a cabo una acción determinada (encender la luz).

Perlocución. Y ha sido influenciado para realizar la acción que ha sido ordenada por $\mathrm{X}$ (encender la luz).

Ya que para que el acto de habla de $\mathrm{X}$ resulte exitoso es preciso que $\mathrm{Y}$ efectivamente encienda la luz, debieran haberse tenido en cuenta reglas tales como: i) la oración formulada debe ser comprensible para el destinatario de la orden, en este caso Y; ii) El destinatario (Y) debe reconocer al hablante (X) alguna autoridad para influir en sus conductas, en este caso, encender la luz; y iii) lo mandado (encender la luz) no debe entrar en tensión con otras órdenes más fuertes que previamente hubieren sido dadas al destinatario (la policía ordenó a Y mantener su casa en penumbras), ni tampoco con creencias ('si enciendo la luz provocaré un corto circuito') o deseos ('no quiero que X note que he estado llorando'), cuyo acatamiento pudiere resultar más valioso que una eventual sanción asociada al incumplimiento de la orden.

Sin embargo, puede que $\mathrm{X}$ sólo pretenda fastidiar a $\mathrm{Y}$ (ilocución), en cuyo caso el esfuerzo comunicativo de $\mathrm{X}$ se verá satisfecho en la medida que $\mathrm{Y}$ efectivamente se sienta molesto (perlocución). Entonces, si Y efectivamente se siente molesto con $\mathrm{X}$ (siendo indiferente que encienda o no la luz), el acto de habla habrá resultado exitoso desde el punto de vista del hablante.

Si nos situamos en el contexto de un proceso judicial cuya consecuencia más relevante -al menos, desde el punto de vista de las partes- será la obtención de determinados beneficios (tuición de una hija, pago de una indemnización, etc.), o bien la imposición de ciertas cargas sobre la parte contraria (encarcelamiento del acusado, constitución de una limitación al dominio, etc.), sería de esperar que los actos de lenguaje de los abogados se orienten precisamente a obtener las finalidades esperadas por sus representados. En ese sentido, el efecto perlocucionario: "el juez se sintió convencido de aquello que le fue dicho y está dispuesto a utilizarlo como razón que sirve de soporte a su decisión”, resultará central para llegar a entender los actos de habla de los abogados en un proceso, lo que debiera llevarnos a indagar acerca de las causas que explicarían por qué los jueces aceptan determinadas clases de discursos y rechazan otras. Por supuesto, podremos hallar una multiplicidad de situaciones en que ello dependerá de circunstancias tan variadas como lo son las experiencias previas de los jueces, las creencias arraigadas en la comunidad de los abogados o las expectativas que se pretende sean satisfechas por los jueces al momento de adoptar una decisión. Sin embargo, hay algunas de estas razones que gozan de un status privilegiado, por cuanto permitirían a los jueces 'justificar' la adopción de una determinada decisión por sobre otras alternativas en competencia; y esto por cuanto en los procesos judiciales el mecanismo de selección de los fragmentos discursivos que se incorporan a una sentencia pasa porque éstos sean entendidos como aptos para conectar a uno o más individuos con la condición de aplicación de una norma relevante para el caso. Para tales efectos se requiere de: i) la selección de reglas o principios entre varios posibles candidatos, lo cual tendrá que ver principalmente con la determinación de su validez en conformidad a una cierta 
ideología básica ${ }^{5}$ (por ejemplo, pertenecen al sistema jurídico las normas que han sido dictadas siguiendo cierto procedimiento', o que sean justas, o que hayan sido inferidas de lo que previamente ha sido resuelto por otros tribunales); ii) la determinación de su significado (por ejemplo, las normas deben ser interpretadas respetando la intención atribuible al legislador, o bien guardando coherencia con otras normas ya interpretadas que pertenezcan al sistema, o en su defecto, cautelando que no se produzcan resultados que perjudiquen a la mayoría.); y iii) la producción de suficiente información para poder dar por probado que el asunto juzgado es un caso encasillable en la categoría definida en la condición prevista en la norma como antecedente para su aplicación. Es respecto a esto último que la 'verdad' pudiere ser especialmente relevante. ${ }^{6}$

\section{II. ¿Y QUÉ ES LA VERDAD?}

En lo que sigue, se darán algunas pinceladas acerca de algunas de las dificultades que el uso de palabras tales como 'verdad', 'verdadero', 'falsedad' o 'falso' presentaría en el contexto del razonamiento judicial. Tales problemas pueden situarse en dos grandes niveles: el primero tiene que ver con la pregunta ¿qué es lo que ha querido decirse cuando se ha sostenido que cierta proposición es verdadera?; y el segundo, con la interrogante acerca de ¿cuáles serían las propiedades que debiera presentar un enunciado cualquiera para llegar a ser calificado como verdadero? El primer nivel de problemas sería metalingüístico, esto es, tiene que ver con la clarificación de lo que ha querido decirse en oraciones en las que ha sido sostenido que 'algo es verdadero' o bien que 'algo es falso'. El segundo nivel de problemas sería, en cambio, de carácter epistémico, esto es, apunta a las circunstancias que tendrían que producirse para efectos de que una determinada proposición llegue a ser calificada como 'verdadera' o 'falsa'.

En el primer nivel se ubica la vieja pregunta “¿Qué es la verdad?” formulada por Poncio Pilato a Jesús de Nazareth, luego de escucharlo decir: “...para esto he venido al mundo: para dar testimonio de la verdad. Todo el que es de la verdad escucha mi voz". ${ }^{7}$ En la referida pregunta, Pilato situaría el foco de atención en el significado que podría atribuirse a la palabra 'verdad' en el discurso escuchado y, no en el problema de si efectivamente Cristo da testimonio de la verdad, o de si quienes son de la verdad escuchan la voz de Cristo. En cambio, la afirmación 'es falso que Graham Bell haya inventado el teléfono’, plantea un problema de los que se ha llamado del segundo nivel, por cuanto lo central de la oración apunta a que Graham Bell -en

${ }^{5}$ Cfr. Ross, Alf. "Sobre el derecho y la justicia”, 5a ed., EUDEBA, Buenos Aires, 1994, pp. 73-104.

${ }^{6}$ Es posible, sin embargo, utilizar el criterio de verdad para efectos de evaluar la tarea interpretativa. Para estos efectos se ha hablado de interpretación -conocimiento para diferenciarla de la interpretación- decisión (u operativa). Los jueces sólo realizan esta última clase de interpretación. Guastini, R. "Distinguiendo" Gedisa, Barcelona, 1999, pp. 203-204.

7 Jn 18, 37-38. 
contra de lo que se había creído por décadas- no habría llevado a cabo las acciones necesarias para calificarlo como inventor del teléfono.

La diferencia entre ambos niveles fue claramente advertida por Alfred Tarski en un aplaudido trabajo publicado en la mitad del siglo $\mathrm{XX}^{8}$ y citado profusamente hasta el día de hoy. ${ }^{9}$

A partir de la oración: "la nieve es blanca" es verdadera si y sólo si la nieve es blanca, Tarski construye la siguiente fórmula genérica en la cual el nombre de la oración -que es el que aparece entre comillas- es reemplazado por el símbolo $X$ y la segunda parte, que es la oración misma por el símbolo $p$. A la equivalencia la llama (T)

(T) $X$ es verdadera si, $y$ sólo si $p$.

Tarski se refiere así a las condiciones para que un acto lingüístico llegue a ser exitoso, esto es, a las condiciones para que determinada proposición pueda ser calificada como 'verdadera'. 10

Para determinar la verdad de una oración es necesario, entonces, tener claridad acerca de las propiedades relevantes para considerar que un enunciado es verdadero; como también, si tales propiedades concurren en el caso concreto. ${ }^{11}$ Desde una perspectiva correspondentista, un enunciado verdadero daría cuenta de la realidad tal cual es o ba sido, en cambio, uno falso constituiría una representación errada de la realidad, es decir, 'lo verdadero' y 'lo falso' representarían ciertos tipos de relaciones que se darían entre las palabras y el mundo. ${ }^{12}$ Las teorías coherentistas, en cambio, sostienen que el juicio de verdad es un asunto que se resuelve en último término a nivel de coherencia entre distintas creencias aceptadas o por la aplicación de otro criterio, que lleva a que las proposiciones nunca sean testeadas con la realidad. ${ }^{13}$

8 Tarski, A.. "La concepción semántica de la verdad y los fundamentos de la semántica”, en Bunge, M. (ed). Antología semántica, Nueva Visión, Buenos Aires, 1960, pp. 111-157. En cuanto a los criterios que permitirían llegar a establecer que una proposición es verdadera o falsa, Tarski es de la opinión que no existen mecanismos que permitan sostener indefectiblemente que una teoría es preferible a otra, lo que no obsta a que puede recurrirse a criterios débiles que proporcionen, al menos, una ayuda en dicha tarea.

${ }^{9}$ Una muy entusiasta defensa de los planteamientos de Tarski puede verse en Popper, K. "Conjeturas y refutaciones. El desarrollo del conocimiento científico”. $1^{\text {a }}$ ed. (2a reimp.), Paidós, Barcelona, 1989, p. 273 y ss. Autores como Putnam, en cambio, se muestran críticos al indicar que "a pesar del invalorable aporte técnico de Tarski, en su obra no se hace nada por explicar la noción de verdad”. Putnam, H. "El pragmatismo”. Gedisa, Barcelona, 1999, p. 25. En el ámbito jurídico ver, por ejemplo, a Ferrajoli, L. "Derecho y razón. Teoría del garantismo penal”. $2^{a}$ ed. Trotta, Madrid, 1997, p. 49.

10 Tarski, A. "La concepción semántica de la verdad y los fundamentos de la semántica”, en Bunge, M. (ed). Antología semántica, Nueva Visión, Buenos Aires, 1960, pp. 150-151.

${ }^{11}$ Popper, K. "Conjeturas y refutaciones. El desarrollo del conocimiento científico". $1^{\mathrm{a}}$ ed. ( $2^{\mathrm{a}}$ reimp.), Paidós, Barcelona, 1989, p. 274.

12 Cfr. Aristóteles. "Metafísica”, Gredos, Madrid, 1994, Libro IV, cap. 7, 1011 b, p. 198.

${ }^{13}$ Sobre la no distinción entre propiedades definitorias de verdad y criterios para determinar la verdad de un enunciado en que incurrirían las teorías coherentistas, ver Goldman, A. "Epistemology and cognition", (5 reimp.), Harvard University Press, Cambridge, Massachusetts and London, 1986, p. 144. 


\section{A. ¿Qué entendemos por verdad en el ámbito jurídico?}

La distinción entre lo verdadero y lo falso opera como criterio de demarcación entre aquellos enunciados que pueden válidamente ser utilizados en ciertos textos y discursos, y aquellos enunciados que, en cambio, deben ser desechados. Así, por ejemplo, en un congreso de física no podría plantearse impunemente que puedo coger estrellas con la mano, y sí, en cambio, que “...hay una discrepancia entre las velocidades rotacionales observadas de las estrellas de las regiones exteriores de las galaxias espirales... y las velocidades que esperamos según las leyes de Newton a partir de la distribución de las estrellas visibles de la galaxia"; ${ }^{14}$ ello por cuanto, lo primero sería evidentemente falso dado el cuerpo de creencias compartido, en cambio, para lo segundo se contaría con buenas razones para considerarlo como verdadero. La existencia de este criterio de demarcación no impide -sin embargo- que en otros contextos comunicativos (por ejemplo, mientras estamos jugando con nuestra hija) podamos decir: 'Margarita ha cogido una estrella con la mano'. Más aún, en estos casos, al aplicarse criterios distintos de selección de enunciados perfectamente podríamos dejar fuera algunas oraciones con aspiraciones de verdad como lo sería aquella que habla de la discrepancia entre las velocidades rotacionales observadas de las estrellas de las regiones exteriores de las galaxias espirales...

Conscientes de las complejidades que trae consigo la construcción de discursos que pudieren ser calificados como representativos de la realidad, los abogados hemos, con frecuencia, apelado a una categoría de status inferior al de la verdad tout court, cual es la de 'verdad formal', con miras a vincular a un individuo concreto con el caso abstracto previsto en una norma jurídica. De esta manera, podemos indicar que la búsqueda de la verdad es una tarea respetable, pero que para nuestros fines prácticos bastará una conexión que supere los borrosos parámetros definidos en nuestros propios sistemas probatorios y no en los de disciplinas más exigentes. La adopción de este punto de vista permitiría, por ejemplo, considerar al enunciado "Dmitri mató a Fiodor" como formalmente verdadero si superase los test aplicados en el curso de un proceso concreto, ${ }^{15}$ aun cuando desde otras perspectivas (científica, por ejemplo) no pudiere sostenerse seriamente que Dmitri dio muerte a Fiodor. La categoría de verdad formal ha sido puesta en tela de juicio pues en ocasiones provoca más confusión que claridad y lleva a proscribir una forma de crítica justificada frente a la acción de los jueces. Esto tiene que ver con que a diferencia de lo que ocurre con la literatura o con la poesía, la ciudadanía y -al menos- parte de la comunidad de abogados no está dispuesta a dotar al mundo de lo jurídico de un amplio nivel de independencia respecto de otros mundos que estimamos que se encuentran enganchados con la realidad.

${ }^{14}$ Hawking, S. "El universo en una cáscara de nuez". 9a ed., Crítica /Planeta, Barcelona, mayo 2003, p. 186.

${ }^{15} \mathrm{La}$ idea de verdad formal facilita la producción de argumentos tales como 'lo que no aparece en el expediente no existe' y, en general, de un formalismo -a veces útil y a veces inútil- que suele ser fuente de críticas y mofas a jueces y abogados. 
Así, pese al transcurso de muchas décadas, los juicios que terminaron con Sacco y Vanzetti ejecutados o con Alfred Dreyfuss en prisión siguen atormentándonos; y ello - pienso- no se ha debido tanto a la falta de coherencia interna que pudiere haber afectado a las distintas piezas que formaban parte de la argumentación judicial, sino porque lisa y llanamente no podemos hacerlas calzar con nuestras representaciones acerca de las conductas reales de Sacco, Vanzetti y Dreyfuss.

Ante el fracaso de la distinción entre verdad material y verdad formal pareciera más adecuado hablar sencillamente de la verdad como criterio de demarcación o mejor aún de: 'lo probado', lo que no implica que 'lo probado' pueda desentenderse totalmente de 'lo verdadero', al menos como regla ideal. ${ }^{16}$ Razones epistemológicas (el conocimiento siempre es susceptible de ser revisado) y de carácter práctico (las decisiones de los jueces para que tengan sentido deben ser oportunas) llevan a desechar el uso de la verdad a secas como criterio de demarcación. Si se recurre, en cambio, a la categoría de 'lo probado' como mecanismo de selección de enunciados fácticos, serán las pruebas disponibles y un cuerpo de creencias aceptado por la comunidad acerca de cómo ocurren las cosas, ${ }^{17}$ las que darán el soporte necesario para que las buenas historias adoptadas por los jueces se entiendan plenamente justificadas; y las malas historias, rechazadas. Una buena decisión judicial será, entonces, aquella que se sustenta sobre una historia probada que al momento de ser formulada pudiere ser calificada como si fuera verdadera.

Este punto de vista no se aleja, en todo caso, mayormente de lo que ocurre en otras disciplinas. Así, por ejemplo, durante el siglo XX el enunciado 'Alexander Graham Bell inventó el teléfono' era calificado como si fuere verdadero; y en el siglo XXI, lo sería ‘Antonio Meucci inventó el teléfono'. El cambio tuvo que ver con la producción de nueva información que probaría que Antonio Meucci habría sido en realidad el inventor del teléfono. Lo mismo ocurre en el ámbito jurídico: la historia seleccionada bajo el rótulo de probada tendrá que ser la candidata que al momento de ser escogida se presente como la más plausible, esto es, la que mejor se ajuste a la información disponible. Una historia así contará con las credenciales suficientes para ser considerada como si fuese verdadera, aun cuando nunca estemos seguros de que efectivamente lo sea.

Para calificar a una historia como si fuere verdadera, o bien con el status de que 'está probada', se esperaría que aquélla se adecue a un cuerpo de conocimientos asentado que

${ }^{16}$ De acuerdo a esta regla ideal, se podrá presionar al legislador para que ajustase -en la medida de lo posible- los mecanismos probatorios del sistema jurídico a aquellos más reputados en disciplinas científicas; como también, se podrán llenar los amplios espacios de discrecionalidad con la que cuentan los jueces con reglas que se reconocen como aptas para la adecuada selección de enunciados fácticos dotados de mayor plausibilidad.

${ }^{17}$ Esto se ajusta a lo señalado en el art. 297 del código procesal penal en orden a que si bien los jueces tienen libertad para valorar la prueba no pueden contradecir las reglas de la lógica, los conocimientos científicamente afianzados y las máximas de la experiencia. 
determina aquello que debe ser aceptado (y que será el que, en definitiva, marcará la diferencia entre las distintas disciplinas). En ocasiones, dicho cuerpo de conocimientos será muy prestigioso como ocurre con las disciplinas teóricas y en otros casos no tanto, como ocurre con algunas disciplinas prácticas (y cuyo caso es el del derecho). Esta diferencia lleva a que en el plano teórico las respuestas siempre sean provisionales, esto es, permeables a cualquier ajuste ante cualquier falla que sea advertida; y a que en disciplinas prácticas las respuestas sean definitivas, aun al precio de tolerar errores (si con ello se evita la inestabilidad u otro efecto pernicioso). Los mecanismos de prueba en uno y otro ámbito no tienen, entonces, porqué ser esencialmente distintos: ${ }^{18}$ más aún, resulta aconsejable que no sean contradictorios entre sí. Esto, sin embargo, no debe llevar a desconocer que es razonable que los mecanismos disponible para asuntos puramente teóricos sean más exigentes que los utilizados en asuntos prácticos. Tal vez la diferencia -como ha señalado Susan Haack al comparar culturas científicas y precientíficas- pase no por recurrir a distintos criterios de prueba, sino por "una mejor disposición (de las culturas científicas o, en lo que aquí se sostiene, de las disciplinas científicas o teóricas) para someter las creencias a la crítica, un mayor conocimiento de las alternativas y, por ende, una apertura más amplia a las cuestiones de justificación”. ${ }^{19}$

Antes de pasar al siguiente punto sólo quisiera advertir que una historia puede (e incluso, en ocasiones, debe) ser considerada como verdadera, no obstante que -de hecho- quien la sostenga no crea en ella.

L. J. Cohen advierte, en ese sentido, que: "Si una persona carece del sentimiento de convicción que $p$, él será correctamente considerado responsable de no aceptar $p$, en el caso que la prueba que $p$ fuere perfectamente adecuada. Si hay demostración médica bien difundida de que una cierta clase de vacunación es beneficiosa para la salud de los niños, los padres que conocen tal información serán responsables de no llegar a las conclusiones apropiadas". ${ }^{20}$

B. ¿Cuáles son las condiciones que debieran cumplir los enunciados fácticos para ser considerados como si fueren verdaderos, en el ámbito jurídico?

Los jueces disponen (o debieran disponer) de un cuerpo de saberes apto para identificar e interpretar normas de manera adecuada, al menos en los llamados casos fáciles. En cambio, en lo que respecta a la determinación del discurso de los hechos, los tribunales

${ }^{18}$ Cfr. Cohen, L. J. "Freedom of proof", en Twining, W.; Strein A. (eds.) Evidence and Proof. Darmouth, Aldershot, 1992, p. 3-23 y Hacking, I. "The emergence of probability", Cambridge University Press, Cambridge, 1975.

${ }^{19}$ Haack, S. "Evidencia e investigación. Hacia la reconstrucción en epistemología”, Tecnos, Madrid, 1997 , p. 284.

20 Cohen, L. J. "Belief and acceptance", en Mind, vol. XCVIII, 1989, p. 370. Cfr. Ullman-Margalit, E.; Margalit, A. "Holding true and holding as true", en Synthese, vol 92, año 1992, pp. 170-171, 176. 
no suelen contar con suficientes recursos cognitivos. ${ }^{21}$ Es por ello que en los juicios se precisa la participación de testigos, peritos y también de abogados. Los abogados deben, entonces, gestionar la producción de información relevante para cada juicio, como también proponer posibles historias que le den sentido al conjunto, es decir, tendrán que buscar y seleccionar posibles fuentes de información, como asimismo, proveer de esquemas de interpretación que le den sentido a la información producida. La manera en que los abogados construyan y ordenen los datos presentados con la expectativa de que lleguen a conformar 'lo que ha sido probado', debiera ser escrutada bajo el prisma de un principio básico para la legitimidad de los sistemas jurídicos y que tiene que ver con que los conflictos de intereses sean resueltos en conformidad a lo estipulado en ciertas reglas generales. Hablamos, entonces, de estado de derecho o de principio de legalidad en la medida en que exista un razonable nivel de previsibilidad en las decisiones de los jueces, esto es, cuando la solución prevista en las reglas reconocidas como válidas del sistema jurídico se hace regularmente recaer en las personas que dieron vida a un caso individual encasillable en su respectiva condición de aplicación.

En un pasaje frecuentemente citado, Alchourrón y Bulygin han señalado que "Un fracaso en la determinación de la verdad - mientras sea excepcional- no invalida la decisión del juez, que es considerada válida y produce por ende todos sus efectos jurídicos. Este es el precio que el derecho está dispuesto a pagar en aras de la seguridad y de la paz social, esto es, poder resolver los conflictos sociales dentro de ciertos límites temporales. Pero si los jueces basaran sus decisiones como regla en enunciados empíricos falsos, todo el sistema del derecho se subvertiría. Es importante subrayar que la norma del derecho penal estipula el deber de sentenciar a aquellos que han cometido homicidio y no a aquellos de los que el juez dice que han cometido homicidio... si los tribunales sentenciaran sistemáticamente a los que no han cometido homicidio, es decir, si la norma fuera violada permanentemente, tal norma dejaría de existir". 22

Pese a lo señalado, es indudable que la decisión judicial que sirve para dar por probados ciertos hechos goza de un carácter constitutivo o realizativo, ${ }^{23}$ por el hecho de haber sido dictada por un tribunal competente que se ha sometido a cierto procedimiento. Ahora bien, las reglas que estipulan las condiciones para que un enunciado pueda llegar a tener el carácter de probado suelen dar un amplio margen de discrecionalidad a los jueces, lo que lleva a considerar como una ingenuidad la pretensión de que exista una sola respuesta correcta. La parcial excepción a ello estaría dada por los sistemas de

${ }^{21}$ Cfr. Carnelutti, F. "La prueba civil”. Ediciones Arayú, Buenos Aires, 1955, p. 77-78 (nota 131).

${ }^{22}$ Alchourrón, C. y Bulygin, E. "Los límites de la lógica y el razonamiento jurídico"/en/ ID. Análisis lógico y derecho, Centro de Estudios Constitucionales, Madrid, 1991, p. 313.

${ }^{23}$ Kelsen sostiene este punto de vista, en términos algo exagerados. Kelsen, K. "Teoría pura del derecho”. 9a ed., Porrúa, México, 1997, p. 249. 
si no bubiere sucedido por razones de respeto a derechos fundamentales, pragmatistas o de otra naturaleza; y al igual que lo que ocurre en todo problema práctico, llega un momento en que la decisión del juez va perdiendo sentido habida consideración del tiempo transcurrido, como también porque una permanente inestabilidad en los derechos y obligaciones trae aparejados efectos perniciosos; en vista de ello las decisiones tienen el carácter de definitivo aun cuando pudieren haberse construido en una errada representación de la realidad o identificación de las normas. ${ }^{31}$

En consecuencia, si bien es cierto que sobre los jueces existe una presión en orden a que sus decisiones dispongan de un soporte fáctico anclado en cierta medida en la realidad, tal exigencia es más débil que la que existe en otros contextos y ello tiene que ver con la necesidad de otorgar respuestas oportunas que impiden extender las discusiones por largo tiempo (como si es posible en otros contextos), por la necesidad de resguardar ciertos derechos fundamentales (algunos de los cuales también influyen en las investigaciones que se desarrollan en ámbitos no propiamente jurídicos) ${ }^{32}$ y de seguir ciertas formas estandarizadas de procedimientos. ${ }^{33}$

\section{III. ¡NO MENTIRÁs!}

Hasta este momento, se ha explorado el significado del vocablo verdad vinculado a una cierta forma de relación entre las palabras y el mundo. La palabra (decir la) verdad se refiere, además, a la consistencia entre las palabras expresadas y las creencias del hablante, con lo que se haría alusión, eminentemente, a un juicio de sinceridad. Con este significado tiene que ver el mandato 'debes decir la verdad' o 'no mentirás', el cual cobra fuerza en la medida en que a un acto de habla le sean atribuidas pretensiones descriptivas, esto es, resulta aplicable cuando el hablante se sitúa en espacios de comunicación en los cuales distintos partícipes intentan establecer una forma de relación fuerte entre el significado de las palabras emitidas y el mundo del que pretenden dar cuenta. En la medida en que todos los participantes se comprometan a decir la verdad será más fácil alcanzar la meta ideal consistente en llegar a conocer las cosas de la manera en que efectivamente se producen.

${ }^{31}$ Cfr. Hart, H.L.A. "El concepto de derecho". 2a ed. Abeledo-Perrot, Buenos Aires, 1977, pp. 176-183.

32 Piénsese en la prohibición de tortura o de realización de ciertas formas de experimentación sobre las células madres. Más propiamente jurídicas podrían ser los requerimientos de acusación previa, derecho del acusado de guardar silencio, etc.

33 Estas formas, en muchas ocasiones, también garantizan derechos fundamentales; sin embargo, en otras constituyen rituales que no sirven para tales efectos de tutela, ni tampoco apuntan al logro de mejores decisiones, como ocurre, por ejemplo, con ciertos supuestos de restricción en la admisibilidad de la prueba y de reglas sobre valoración de la prueba que amarran a los jueces y les impiden ajustarse a criterios más adecuados desde una óptica epistemológica (algunos ejemplos pueden observarse en nuestro código de procedimiento civil). 
La obligación de decir la verdad no nos exige que nuestras proposiciones sean verdaderas, sino que apunta fundamentalmente a que nuestros textos o discursos sean consistentes con aquello que consideramos como si fuera verdadero. ${ }^{34} \mathrm{El}$ reproche a la mentira, por su parte, tiene que ver en parte con una inconsistencia entre lo que el hablante cree y lo que el mismo hablante declara (aun cuando en este caso no hay un total desentendimiento con la falsedad de las proposiciones formuladas). Lo medular para el reproche moral tiene que ver con la falta de consistencia entre nuestras creencias y nuestros actos de habla, y no tanto con la falsedad de las proposiciones, sin perjuicio que lo primero muchas veces lleve aparejado lo segundo.

Así, por ejemplo, para que la declaración de Grigorii: 'Dmitri mató a Fiodor' sea una mentira será necesario que Grigorii no crea que Dmitri mató a Fiodor y que Dmitri efectivamente no lo haya matado. Si falla cualquiera de las condiciones difícilmente calificaremos la afirmación de Grigorii como una mentira. Si Grigorii creía que Dmitri mató a Fiodor no obstante que en la realidad fue Pavel, le podremos reprochar su ingenuidad, su falta de prolijidad pero no su falta de honestidad o mentira (el reproche moral también podría ser fuerte si Grigorii hubiere estado en condiciones de llegar a saber que Pavel era el homicida y no hizo nada para averiguarlo). Ahora bien, si Dmitri hubiere sido quien efectivamente mató a Fiodor, la afirmación de Grigorii habría resultado verdadera. La acción de Grigorii quien no declaró en conformidad a sus creencias quizás no sería tildada de mentira, ya que de hecho resultó ser verdadera (quiso mentir pero no le resultó). La condición de falsedad de la proposición operaría a la manera de las 'condiciones objetivas de punibilidad' de las que habla el derecho penal para hacer referencia a ciertas circunstancias que escapan absolutamente al dolo o imprudencia del autor y cuya ausencia podría llevar a la no aplicación de la pena.

Si nuestros interlocutores nos comunican como si fuera verdadero aquello que ellos creen que efectivamente es cierto, debiera resultar más fácil alcanzar la meta cognitiva que se asocia a la generación, eliminación, modificación o fortalecimiento de creencias. Así, será posible relajar el filtro de aceptación de la información provista por terceros, ya que lo dicho correspondería a lo que los hablantes efectivamente han pensado o han percibido (o cuando menos lo que se creen haber percibido). No es de sorprender, entonces, que un conocido autor haya sugerido que en nuestras conversaciones opera una regla de calidad según la cual: los hablantes deben tratar que sus contribuciones sean verdaderas.

La 'súper máxima de calidad': 'cada hablante debe tratar que sus contribuciones sean verdaderas', de la que habla Paul Grice en Logic and conversation, ${ }^{35}$ es aplicable a

${ }^{34}$ Bruno Celano observa que sobre los jueces no podría haber una obligación de descubrir la verdad, sino que a lo más podría exigírseles que la busquen lo mejor que puedan. Celano, B. "Decisión judicial y verdad”, en Comanducci, P. Análisis y derecho, Fontamara, México D. F., 2004, pp. 138-143.

${ }^{35}$ Grice, P. "Logic and conversation", en Id. Studies in the way of words. Harvard University Press, Cambridge (Mass.) - London, 1989, p. 27. 
muchas de nuestras conversaciones, por cuanto su violación provocará en el auditorio decepción, franca molestia o sencillamente de sensación de perder el tiempo. ${ }^{36} \mathrm{De}$ esta manera, si en el marco de una conversación nos preguntasen por el resultado de un examen o el pago de una deuda, no sería de extrañar que nos molestásemos si habiendo dado ya una respuesta completa, la pregunta volviese a ser formulada por la misma persona o por un tercero que ya la había escuchado. El principio de cooperación y, en específico, esta súper máxima de veracidad traen aparejados que lo que nosotros decimos será interpretado como si fuese cierto.

Sin embargo, los contextos en que se producen las conversaciones son múltiples, siendo admisible en ocasiones ya sea decir algo que creemos que es falso o bien sobre lo que carecemos de pruebas y, tanto en uno como en otro caso, no habremos violado regla alguna. Es así que en el marco de una conversación podemos bromear, fantasear, ironizar o usar metáforas, ${ }^{37}$ todas situaciones en las que se anula la exigencia de 'hacer contribuciones verdaderas'. Esto lleva a Wilson y Sperber a poner en entredicho la exigencia de verdad planteada por Grice y proponer en su reemplazo una máxima de relevancia. ${ }^{38}$ Para ellos "una declaración es relevante cuando quien escucha, dada su disposición cognitiva y el contexto, es probable que derive genuino conocimiento de ella", lo que no quita que en ocasiones debamos decir la verdad, pero que, a la vez, no constituye impedimento para que en otros casos nos liberemos de dicha exigencia.

En el plano teórico, la información fidedigna nos ayudará a disponer de una imagen más plausible de la realidad, esto es, a conocer las cosas de manera más próxima a como efectivamente son, puesto que el conocimiento de lo externo al sujeto no sólo tiene que ver con la percepción directa de éste, sino también con experiencias proveídas por terceros.

Pese a la existencia de barreras epistémicas que hacen dudoso o imposible llegar a sostener que algo es verdadero, la pretensión última de la ciencia tiene que ver con la descripción de la realidad tal cual es. ${ }^{39}$ Ello explica que las teorías sean abandonadas cuando ellas comiencen a presentar fallos importantes, que -por regla general- tendrán que ver con la imposibilidad de hacerse cargo de las consecuencias que podrían extraerse de observaciones calificadas de fiables. Así, Karl Popper

${ }^{36}$ Cfr. Chiassoni, P. "Los juegos interpretativos. La interpretación de la ley desde un enfoque griceano", en Navarro, P. y Redondo M. C. La relevancia del derecho, Barcelona, Gedisa, 2002, p. 203.

${ }^{37}$ Grice está consciente de ello pero, probablemente, no saca todas las consecuencias que habría sido esperable.

38 Wilson, D.; Sperber, D. “Truthfulness and relevance”/en/ Mind Vol 111, july 2002, p. 599.

${ }^{39}$ Desde cierto punto de vista pragmatista, no tiene sentido preguntarse acerca de la existencia de una realidad externa al sujeto, por cuanto actuar cómo si existiera una realidad externa es útil para jugar los juegos de lenguaje en los cuales ésta es presupuesta. Rorty, R. "Does academic freedom have philosophical presuppositions?"/en/ Academe, nov - dec 1994, pp. 56-57. 
uno de los teóricos de la ciencia más influyentes en el siglo XX, señala al test de la falsabilidad como la clave que determina que un enunciado tenga el carácter de científico: en el momento en que se demuestra que un enunciado es falso, debe ser eliminado. ${ }^{40}$

Por su parte, en asuntos prácticos, la información fidedigna nos ayuda a tomar mejores decisiones por cuanto el resultado obtenido debiera, por regla general, aproximarse en mayor medida a las que eran nuestras expectativas. ${ }^{41}$ Que se diga la verdad contribuye a la toma de buenas decisiones, pues los enunciados verdaderos nos permitirán predecir de manera más fiable nuestros futuros cursos de acción, como también, justificar los que ya han sido adoptados. ${ }^{42}$ Según lo expresado, existirían razones fuertes para que cuando nos comuniquemos digamos la verdad y así es reconocido por nuestras concepciones morales. Quienes dicen la verdad generan confianzas, son admitidos en nuestros círculos más íntimos; al contrario, cuando nos enteramos que alguien nos ha mentido nos sentiremos enormemente frustrados, las confianzas se quiebran y el mentiroso podrá llegar a ser marginado de las comunidades a las que pertenecía. ${ }^{43}$ Sin embargo, en el terreno práctico la pretensión de llegar a operar con discursos calificables de verdaderos no siempre constituirá una exigencia intransable. ${ }^{44}$ En este ámbito los problemas no permanecen eternamente abiertos, como también no es tan raro que el valor verdad pueda llegar a ser derrotado por otra clase de consideraciones.

Un buen ejemplo en el sentido de que la verdad no siempre es el factor clave para la asignación de cargas y/o beneficios lo podemos encontrar en el código civil a propósito de la filiación. En las reglas que regulan su determinación, hay un delicado equili-

${ }^{40}$ De hecho, quienes se niegan a revisar creencias que parecían asentadas cuando son desafiadas por nuevas teorías serán tildados de dogmáticos o con otro calificativo similar y ese acto puede llevarlos a su marginación de la comunidad científica.

${ }^{41}$ Cfr. Resnik, M. "Elecciones. Una introducción a la teoría de la decisión”. Gedisa, Barcelona, 1998, p. 35.

42 Así, sería una decisión perfectamente racional aquella que ha considerado información de buena calidad y una adecuada predicción de las posibilidades de éxito de las distintas alternativas en competencia, a pesar de que en los hechos dicha decisión nos lleve a perder mucho dinero o a pasar un muy mal rato.

${ }^{43}$ En varios de los grandes escándalos políticos del siglo XX, un aspecto central del repudio tuvo que ver tanto con la realización de una conducta dañosa, como con la falta de reconocimiento oportuno. Así, por ejemplo, John Profumo, ministro de defensa británico, se retira de la política en 1963 luego que se demostrara que había mentido al Parlamento británico respecto de su relación con la prostituta Christine Keeler, quien, a la vez, era amante del agregado naval y espía soviético Evgene Ivanoven. Diez años más tarde, la declaración de Richard Nixon en la TV según la cual no había sabido del espionaje en la sede del partido demócrata en Washington (Watergate), sino en marzo de 1973 - siendo que en realidad seis meses antes había estado al tanto de ello- fue un aspecto clave para su abandono de la Presidencia de los Estados Unidos.

${ }^{44}$ Chiassoni distingue entre juegos cognitivos y juegos prácticos. La regla básica para la selección de objetivos de los juegos prácticos sería: "Las L - formulaciones y las L - inscripciones deben interpretarse de modo tal que aseguren mejor nuestros intereses prácticos no - cognitivos". Chiassoni, P. "Los juegos interpretativos. La interpretación de la ley desde un enfoque griceano", en Navarro, P. y Redondo M. C. $L a$ relevancia del derecho, Barcelona, Gedisa, 2002, p. 198. 
brio entre el resguardo de la paternidad biológica y la que podría llamarse afectiva, al hacerse prevalecer la posesión notoria del estado civil de hijo sobre las pruebas periciales biológicas, salvo que esto fuere inconveniente para el hijo. ${ }^{45} \mathrm{Un}$ caso en sentido inverso -en que parece buscarse la verdad a ultranza y que aparentemente desafiaría lo recién señalado- corresponde a la revisión de las condenas aplicada a personas fallecidas ${ }^{46}$ por cuanto sus efectos prácticos son escasos o nulos, al incidir únicamente en nuestro cuerpo de creencias y en nuestros sentimientos, mas no en la persona a la que se le impuso injustamente una pena.

La regla que nos dice que debemos decir la verdad no opera como una regla absoluta, sin posibilidades de excepción. En ciertas situaciones, un auditorio perfectamente racional podría estar de acuerdo en que no resulta valioso decir la verdad. Sostener que no hay excepciones al deber de decir la verdad podría ser señal de una actitud reverente ante las reglas. El deber decir la verdad puede requerir ser ponderado con otros valores, operación en la que podría resultar derrotado.

Mentir sobre el crítico estado de salud de un pariente puede ser una conducta apropiada si así se disminuyen las altas posibilidades de infarto al miocardio del conductor del automóvil que acaba de chocar. Por su parte, Guido -protagonista de La vita è bella- nos conmueve cuando miente a su hijo para efectos de sustraerlo de los horrores que se viven en el campo de concentración.

\section{LA FÁBRICA DE HISTORIAS}

En Rashomon -película dirigida por Kurosawa e inspirada en el cuento En un Bosquecillo de Akutagawa- el espectador queda perplejo ante las distintas historias que se presentan a un tribunal con el propósito de explicar el hallazgo del cadáver de un samurai en un bosque y la violación de una mujer. Las dudas podrían diluirse si se asumiere que algunos o todas las personas implicadas -el bandido Tajomaru, la mujer del samurai y la víctima (a través de un médium) - han mentido al dar cuenta de la historia que servirá de soporte a la aplicación de una pena. Una forma alternativa de entender los disensos -y que no es excluyente de la anterior- pasa por asumir que las historias no se encuentran plenamente determinadas por los hechos observados, sino que son la resultante de un cúmulo de circunstancias, tales como, los límites del lenguaje mediante el cual nos comunicamos, las creencias previas de quienes las elaboran, al estado de avance de la ciencia, o sencillamente, nuestros deseos. Las historias distan de ser una aséptica descripción de la realidad, son encadenamientos que nos sirven para dar sentido a una serie de acontecimientos que, de otra manera, se presentarían inconexos. Parafraseando

\footnotetext{
45 Art. 201 del código civil.

${ }^{46}$ Ver artículo 473 del código procesal penal.
} 
a Quine -al dar cuenta de la elaboración de las teorías físicas- se podría decir que nuestras historias son construidas con un uno por ciento de observación y noventa y nueve por ciento de conceptualización. ${ }^{47}$ En la construcción de historias que se presentan en sede judicial no se trata de que todo vale, pues hay reglas de admisibilidad y a veces de valoración de la prueba que contribuyen a la determinación de cuáles serían las conceptualizaciones posibles; sin embargo, ello no incide en que de todas formas se trate de historias que se sustentan en materiales bastante rudimentarios.

Las razones que conspiran en contra de la existencia de una sola historia tienen que ver, entre otros, con los siguientes factores: i) mayor o menor nivel de abstracción de la explicación, como ocurre con el conocido relato de los tres picapedreros que al ser preguntados acerca de lo que estaban haciendo contestan a su turno: 'estoy picando piedras', 'estoy ganándome el sustento' y 'estoy construyendo una catedral'; ${ }^{48}$ ii) carga teórica de la observación, esto es, el observador tiene ciertas expectativas respecto de lo que va a percibir las que influyen en lo que efectivamente observa ${ }^{49}$ y iii) riqueza o pobreza del lenguaje utilizado para expresar las historias; iv) lagunas de conocimiento que llevan a que aquellos fragmentos perdidos tengan que ser complementados con propuestas que nacen de nuestras experiencias previas, teorías asentadas, etc.

Los principales responsables de construir historias son los abogados. Para entender lo que ellos deben hacer es útil tener en cuenta los distintos escenarios en que operan y cuyos estereotipos podríamos visualizarlos -siguiendo a Damaška- en el modelo de proceso del Estado activista (o de bienestar) que privilegia la implementación de políticas públicas y en aquél propio del Estado reactivo (o del laissez faire) cuya principal meta es la resolución de los conflictos. Si a la adjudicación se asocia el objetivo primordial de implementación de las políticas públicas ${ }^{50}$-plasmadas (adecuada o inadecuadamente) en las normas jurídicas- es deseable el esclarecimiento

${ }^{47}$ Quine, W. V. "Otherwordly”, en The New York Review of Books, Vol. 25, No 18, 23 nov. 1978. Por supuesto, la metáfora toma más fuerza en aquellos casos en que la información de base es más bien escasa. Sin embargo, en todo proceso habrá un porcentaje alto de conceptualización.

${ }^{48}$ Las tres historias son candidatas a verdaderas y no son contradictorias, pero indudablemente algunas pueden ser más interesantes que las otras.

${ }^{49}$ Este fenómeno fue advertido por Kant y por Bentham. En el siglo XX, Norwood R. Hanson, fue uno de los filósofos que llamó más la atención acerca de este fenómeno: "La observación de x está moldeada por un conocimiento previo de x. El lenguaje o las notaciones usados para expresar lo que conocemos, y sin los cuales habría muy poco que pudiera reconocerse como conocimiento, ejercen también influencia sobre las observaciones". Hanson, N. R. "Patrones de descubrimiento. Investigación de las bases conceptuales de la ciencia”. Alianza, Madrid, 1977, p. 99.

${ }^{50}$ Ver Damaška, M. "Las caras de la justicia y el poder del Estado". Editorial Jurídica de Chile, Santiago, 2000, pp. 253 y ss. 
del caso individual bajo una idea de verdad más bien fuerte, ${ }^{51}$ esto es, próxima a lo que se espera para dar cuenta de asuntos teóricos en un determinado momento. La gran meta, de acuerdo a este modelo, será que las cargas y beneficios sean distribuidos exactamente de la manera que ha sido prevista por el legislador. Para tales efectos sería esperable que las historias acogidas por los jueces sean lo más próximas -dentro de lo posible- a aquello que ha ocurrido. Prima facie podría pensarse en el marco de este modelo de proceso en un abogado funcionario -o según comúnmente se dice servidor de la justicia y colaborador de su administración-52 que debe desplegar todos sus esfuerzos en la clarificación del problema que les atañe, independientemente de que ello sea o no favorable a sus clientes. ${ }^{53}$ El otro modelo de proceso -que ha penetrado con cierta fuerza en las últimas décadas en países como el nuestro, tal vez, por el acercamiento entre los sistemas jurídicos de tradición continental y los de raigambre anglosajo$\mathrm{na}^{54}$ - pone su principal énfasis en la resolución de los conflictos que se produzcan entre los ciudadanos, sin importar tanto la clarificación de lo sucedido sino sobre todo la pacificación. ${ }^{55}$ Los jueces sólo intervienen en la medida que les sea solicitado y si bien es cierto existen reglas que regulan la manera de resolver las disputas, éstas son bastante flexibles adaptándose si es necesario a los acuerdos de las partes. Bajo este modelo, pareciera esperarse que los abogados al litigar ejecuten una buena defensa de los intereses de su cliente, lo que obviamente puede llevarlo a entrar en tensión con las aspiraciones propias del modelo anterior. ${ }^{56}$ Aquí, el abogado está irremisiblemente amarrado con una meta del proceso: ¡su cliente debe quedar satisfecho!, ya sea obteniendo la indemnización más suculenta posible, siendo absuelto de todo cargo o bien obteniendo cualquier otro beneficio o liberación de carga. El abogado -desde el punto de vista de este modelo- no está dispuesto a variar su punto de llegada, aun en el caso en que su opción no se le presentare como la más razonable. Exagerando un poco las cosas, se podría decir que su meta es construida independientemente de cualquiera baya sido el mundo en el cual ocurrió la experiencia que pretende ser vinculada con determinada norma jurídica. La idea de verdad que se manejaría en este contexto sería más débil que en el otro modelo.

${ }^{51}$ Cfr. Damaška, M. "Las caras de la justicia y el poder del Estado". Editorial Jurídica de Chile, Santiago, 2000, p. 276-277.

52 Artículo 1 del código de ética. Ver Ruiz-Tagle, P. "Funciones sociales relacionadas con el Derecho" /en/ Id. Derecho, Justicia y Libertad. Fontamara, México D.F., 2002, pp. 29-33.

${ }^{53}$ Una muestra de ello puede observarse en el artículo 32 del código de ética que señala: "Cuando el abogado descubre en el juicio una equivocación que beneficie injustamente a su cliente o una impostura, deberá comunicárselo para que rectifique y renuncie al provecho que de ella pudiere obtener. En caso que su cliente no esté conforme, puede el abogado renunciar al patrocinio".

${ }^{54}$ Ver Taruffo, M. "Modelli di prova e di procedimento probatorio", en Rivista di Diritto Processuale, $1990 \mathrm{~N}^{\circ} 2$, p. 446-447.

55 Damaška, M. "Las caras de la justicia y el poder del Estado". Editorial Jurídica de Chile, Santiago, 2000, p. 169 y ss. (especialmente 212-213).

${ }^{56}$ La tensión entre ambas visiones de los abogados están bien tratadas en Peña. C. "Notas sobre abogados y educación legal. (Borrador para comentarios)", en http://islandia.law.yale.edu/sela/penas.pdf 
La posición del abogado se asemeja a la del estudiante enfrentado a un problema matemático que aparece en su libro de texto. Si el desarrollo realizado no ha sido apto para arribar a la meta esperada (el resultado que aparece en las últimas páginas del libro) se revisará el procedimiento utilizado y será reemplazado por otro que permita establecer la ligazón entre el problema y la solución. En ocasiones, esto implica realizar muchas veces la operación. De la misma manera, los abogados se esmeran en buscar rutas que le lleven al destino deseado, lo que implicará examinar leyes, decretos, opiniones, sentencias, declaraciones, etc. Para ello será preciso dejar de lado aquellas alternativas que -aun siendo plausibles- desvían de la meta esperada. Se dará especial énfasis a aquellos aspectos que ayuden a consolidar el camino elegido. Puede, eso sí, llegar un momento en que aquello no parezca sostenible y sea necesario preguntarse si se perseverará o no, al igual que en algún momento el estudiante se preguntará si el resultado que aparece al final del libro es efectivamente correcto. Ahí se puede plantear el dilema acerca de si nuestras versiones pueden llegar a transformar los elementos de los cuales disponemos, es decir, si podemos o no transformar u ocultar la información disponible o potencialmente disponible sin dar cuenta transparente de ello.

En la medida que se otorgue primacía al modelo de abogado como auxiliar de la administración de justicia, todas aquellas acciones que pudieren conspirar en contra de la solución más justa posible -entendiendo por tal aquella que puede hacerse calzar de mejor manera con la condición de aplicación de una determinada norma- serán vistas con suspicacia por parte de la ciudadanía y de la comunidad de abogados y jueces. En cambio, bajo el modelo de abogado defensor de los intereses de sus clientes, la realización de acciones que tiendan a una más justa distribución de bienes y de cargas podría ser entendida como un abandono de sus deberes profesionales, si con ello se despilfarrase la oportunidad de obtener mayores ganancias para su cliente.

Si bien es cierto, los ciudadanos involucrados en un litigio judicial -por regla general- esperan de sus abogados que eviten a toda costa que les sean atribuidas cargas especialmente desagradables; al momento de evaluar problemas de los otros suelen abogar por la utilización de una vara más imparcial, según la cual los beneficios y las cargas deben atribuirse sólo sobre quienes hayan incurrido en las casos genéricos señalados en las normas jurídicas. Estas erráticas circunstancias llevan a Rawls -en un contexto más amplio- a concebir un escenario ideal (la posición originaria) para la definición de mecanismos de distribución de los bienes y cargas, en la que se provoca deliberadamente la ignorancia acerca si tales reglas nos beneficiarán o perjudicarán. ${ }^{57}$ Rorty, por su parte, explora el valor justicia como una forma de lealtad a grupos amplios, lo que tiene como efecto el debilitamiento de nuestros

${ }^{57}$ Rawls, John. "Teoría de la Justicia”. (2 $2^{a}$ reimp.), Fondo de Cultura Económica, México D. F., 2000, pp. 119 y ss. 
compromisos con grupos más íntimos en los cuales se expresan con mayor facilidad lo que son nuestros intereses más personales. ${ }^{58}$

La concepción de los abogados como defensores de los intereses de sus clientes se ajusta bien a nuestra tendencia de proteger lo que consideramos nuestro, o en otros términos a la justicia como resultado de una negociación en la cual la parte involucrada espera quedar en la mejor posición posible compatible con el mínimo aceptable por la contraria (siempre bajo el supuesto que sean respetadas algunas reglas mínimas para el intercambio). ${ }^{59}$ Por su parte, la concepción de los abogados como guardianes de la correcta aplicación de las normas jurídicas calza bien con una idea de justicia como imparcialidad, en la que los intereses más egoístas se difuminan. Los modelos presentados raramente se presentan puros, probablemente porque resulta extraño que de los sistemas jurídicos sólo se espere la aplicación a ultranza de aquellas normas jurídicas útiles para implementar políticas públicas, o bien sólo el acuerdo de las partes como resguardo de los planes de vida de los individuos.

Recapitulando parcialmente lo que ha sido dicho hasta este momento, podría sostenerse lo siguiente:

a) En principio, las exigencias de sinceridad y de búsqueda de la verdad que pesan sobre los abogados resultan más débiles que las que se detectan en otros contextos en los cuales la verdad opera como criterio fuerte para demarcar lo que debe y lo que no debe ser aceptado (por ejemplo, discurso científico). Esto es consecuencia de que el lenguaje puede ser utilizado para el logro de distintos fines, con lo que los criterios de demarcación aplicables en ciertos contextos serían inadecuados en otros.

b) A pesar de los intentos desplegados en el ámbito jurídico por entender la verdad formal como un criterio de aceptación de enunciados parcialmente desconectado de lo que ocurre en otros ámbitos de nuestra existencia, podría considerársele como un fracaso pues supone la eliminación de una interesante crítica sustentada en otros sistemas de justificación. Las historias que finalmente adopten los jueces a partir de las sugerencias de los abogados tendrán que ser -a lo menos- plausibles en relación a las representaciones disponibles para otros ámbitos de nuestras vidas que cuenten con pretensiones descriptivas. En la medida en que los enunciados que sirvan para definir el caso específico den cuenta de cierta relación entre las palabras y el mundo será menor el efecto de desmoralización sobre aquella parte que reciba

${ }^{58}$ Rorty, R. "La justicia como lealtad ampliada", en Id. Pragmatismo y política. $1^{\text {a }}$ ed., Paidós, Barcelona -Buenos Aires- México, 1998, pp. 105 y ss.

${ }^{59}$ En cuanto a la manera en que se repartirían las ganancias disponibles por sobre el mínimo que las partes estarían dispuestas a aceptar para no seguir el conflicto, existen distintos puntos de vista que van desde aquellos que apelan a que debe reflejarse el poder efectivo de negociación de cada parte, hasta quienes postulan a la división equitativa entre las partes. Ver Barry, B. "Teorías de la justicia”. (1ª reimp.), Gedisa, Barcelona, 2001, pp. 25 y ss. 
la decisión adversa, como asimismo, serán satisfechos algunos principios claves del sistema jurídico.

c) Para llegar a disponer cualquier sistema de enunciados fácticos potente, es importante que quienes participen en su construcción se comprometan prima facie a decir la verdad. Decir la verdad (o no mentir) no implica una obligación de comunicar enunciados verdaderos sino la de ser sinceros al momento de comunicar mis creencias. Si somos sinceros, podremos ser interpretados como si lo que hemos dicho fuere cierto, es decir, no será necesario incorporar filtros a la información que resguarden posibles fallos debidos a la falta de honestidad del hablante.

d) La realidad se puede reconstruir no sólo desde una única perspectiva sino que, al contrario, da cabida a que a partir de unos mismos hechos no discutidos puedan presentarse distintas historias explicativas. Las decisiones judiciales se construyen bajo el supuesto que cada parte que interviene en un conflicto presenta las mejores historias construidas desde su punto de vista.

e) El discurso de los abogados pretende influir en la manera en que serán construidas las sentencias judiciales. Dependiendo del modelo de proceso imperante y de las funciones que en él correspondan a los abogados, sus acciones deberían orientarse, ya sea a la identificación de la solución más adecuada para el caso concreto habida consideración de lo estipulado en las normas jurídicas vigentes, o bien a la resolución de los conflictos de la mejor forma que sea compatible con las pretensiones de las partes involucradas. En el primero de los casos, las exigencias sobre los abogados de construir historias verdaderas serán mucho más fuertes que en el segundo.

\section{RESPETANDO EL FAIR PLAY}

En lo que sigue se explorarán algunas posibles consecuencias asociadas a las peculiares exigencias de verdad y sinceridad que recaerían sobre los abogados. Según se ha dicho, los límites de sus discursos serán distintos dependiendo del modelo de abogado en el cual estemos pensando. Sin intentar en estas pocas líneas dar argumentos con pretensiones de definitividad, se podría señalar que hay fuertes señales en orden a que nos estamos progresivamente aproximando a un tipo de abogado mucho más comprometido con la defensa de los intereses de su cliente, antes que con el logro de una solución al caso que sea compatible con las políticas públicas expresadas en las normas jurídicas. ${ }^{60}$ Como botón de muestra, puede observarse, por una parte, que se ha instaurado en la presente década un proceso penal que da espacios para la negociación y que opera, en gran medida, bajo una lógica adversarial de la cual se espera que cada parte tenga la posibilidad de defender sus intereses de la mejor manera posible ${ }^{61}$ (el juez dirimirá los

${ }^{60}$ Ver Peña. C. "Notas sobre abogados y educación legal. (Borrador para comentarios)", en http://islandia.law.yale.edu/sela/penas.pdf

${ }^{61}$ Por supuesto, ciñéndose a ciertas reglas que cautelan que ninguna de ellas saque ventajas indebidas de su posición dominante o de su falta de escrúpulos. 
desacuerdos desde una posición imparcial); y por la otra, que se han ido abriendo espacios, en distintos ámbitos de nuestras vidas, a puntos de vista hasta hace poco ahogados y bajo la sola condición que sean adecuadamente fundamentados. ${ }^{62}$

Si se considera el objetivo de resolución de conflictos -asociado en mayor o menor medida a la función de adjudicación- debiera admitirse que los abogados debieran intentar extraer toda aquella información que pudiere favorecer a los intereses de su cliente (inclusive la que pudiere perjudicar a la contraria). No se esperaría, en cambio, que intentasen extraer datos que favorezcan a la contraria, ya sea fortaleciendo la versión de éste o perjudicando la propia historia (aquello será función del otro abogado). Eventualmente, los abogados podrían proveer directamente información pero los sistemas jurídicos, en general, son reacios a ello por su falta de imparcialidad. Es más, los abogados están obligados a guardar secreto respecto de aquella información proveída por su cliente que pudiere perjudicar a éstos. ${ }^{63}$ Esto último lleva, incluso, a que los abogados estén obligados a omitir información o a mentir, para el caso en que no hacerlo permitiere a los jueces inferir consecuencias del silencio.

Por supuesto que sostener que los abogados están autorizados a mentir resulta impopular, pero en ciertas circunstancias el silencio podría equivaler a una aceptación. Así, por ejemplo, sucedió en el siguiente diálogo sostenido por el Premio Nacional de Ciencias Exactas Claudio Bunster (ex Teitelboim) y Fernán Meza, segundo marido de su madre, Raquel Weitzman:

- ¿Soy hijo de Volodia?” (Al otro lado de la línea se produjo un largo silencio y una voz muy seria le respondió)

-"Claudito, hay cosas que no se hablan por teléfono".

- "Ya me has contestado Fernán. Dime algo más: Hay algún candidato a ser mi padre..". 64

Jerome Bruner -en un libro que da nombre al capítulo precedente- da una interesante pista para entender la relativa laxitud al momento de evaluar los discursos de los abogados: “...cómo sorprendernos del hecho de que los relatos judiciales sean considerados con sospecha -no sólo por las partes en conflicto, sino también por quien debe pronunciarse por una u otra-, y con buenos motivos. De hecho, todos saben que, por más que en líneas generales busquen la justicia, sobre todos estos relatos dejó su impronta la retórica del egoísmo". ${ }^{65}$ De esta manera, podemos comprender que los discursos de los abogados serán interpretados asumiendo que sus puntos de vista son sesgados, en términos de favorecer el resultado esperado. Si se asume lo anterior, habrá

\footnotetext{
${ }^{62}$ No es que antaño esto no se produjera en algunas comunidades específicas, sino que los espacios donde esto resulta posible se han ido ampliando de manera considerable.

63 Art. 231 del código penal.

${ }^{64}$ Publicado en La Tercera el 4 de septiembre de 2005. Disponible en http://www.latercera.cl

${ }^{65}$ Bruner, J. "La fábrica de historias". 1ª ed. Fondo de Cultura Económica de Argentina, Buenos Aires, 2002, p. 66.
} 
potenciales discursos que podrán ser formulados sin violar las reglas del juego y que permitirán explorar historias que de otra manera quedarían excluidas, empobreciendo así las opciones de resultado (¡no debemos olvidar que no hay solo una historia correcta que dé cuenta de lo sucedido!) En otras palabras, si la obligación de decir la verdad en el contexto de un proceso fuere igual de fuerte que en otros contextos, como lo podría ser una discusión científica, una confesión ante un sacerdote, o una entrevista a publicar en un medio de difusión masiva, habría muchas historias relevantes para la comunidad que quedarían al margen y, tal vez, la reconstrucción de historias terminase de manera demasiado simplificada.

No está de más llamar la atención respecto a que en el debate científico quienes sostienen teorías antagónicas las presentan desde el punto de vista más favorable a su aceptación. Así, cada vez que se enfrenten a un fallo de sus planteamientos harán lo posible por encontrar una mirada que deje a la teoría en pie. Sin embargo, a diferencia de lo que ocurre en sede judicial y, en general, en el terreno práctico, estarán mucho más propensos a abandonar sus teorías desde el momento en que los fallos sean insoportables. No hacerlo pudiera llevar a su marginación de la comunidad a la que pertenecen.

Lo expresado puede implicar que los requerimientos acerca de la verdad en el contenido de los discursos en un proceso sean distintos dependiendo si de lo que se está hablando son hechos primarios ${ }^{66}$ o bien de explicaciones o inferencias a partir de éstos. Entiendo por hechos primarios como aquellos respecto de los cuales hay un bajo nivel de reconstrucción por parte del que los formula y, en cambio, una estrecha conexión con lo que directamente ha(bría) sido observado. Por ejemplo el enunciado "Fulano estaba transpirando a las 16:00 horas del día 7 de noviembre de 2004" sería un hecho primario si quien lo introduce en la audiencia de prueba dice haber visto a Fulano transpirando en esa fecha. En cambio, el enunciado "Fulano estaba nervioso a las 16:00 horas del día 7 de noviembre de 2004" no se construye de la sola observación, pues el nerviosismo no puede ser directamente observado sino inferido de la transpiración, tartamudeo, etc. En las declaraciones de testigos el principal foco de atención está situado en la producción de hechos primarios que son los que permitirán anclar las historias construidas con otros espacios de nuestras vidas o si se prefiere con la realidad. El objetivo de los discursos de los abogados no tiene que ver directamente con la introducción de estos hechos primarios sino con su reconstrucción y su vínculo con el caso. Así a partir del enunciado "Fulano estaba transpirando a las 16:00 horas del día 7 de noviembre de 2004", el abogado podrá proponer que "Fulano estaba nervioso a las 16:00 horas del

${ }^{66}$ En estricto rigor debería hablarse de enunciados sobre hechos primarios. No sólo podrían calificarse de hechos primarios los llamados hechos brutos, sino también los hechos institucionales (de los que habla Searle, J. “Actos de habla". 5 ${ }^{a}$ ed. Cátedra, Madrid, 2001, p. 60), esto es, aquellos que para tener sentido requieren de la aplicación de ciertas reglas, como sería el caso del enunciado 'Mengano pateó un corner', por cuanto si no se tuvieran en consideración las reglas del fútbol, carecería de sentido. 
día 7 de noviembre de 2004" o que "Fulano estaba nervioso porque sabía donde estaba el diamante robado a las 13:00 horas del día 7 de noviembre de 2004”, e incluso que "Fulano robó el diamante", El abogado de la contraparte, podría en cambio señalar que "Fulano estaba transpirando porque hacía calor", o bien que "Fulano se pone nervioso cuando se le acerca un policía aunque no haya hecho nada malo".

En lo que respecta a la introducción de hechos primarios, el control propiamente lingüístico resultará sólo medianamente efectivo ya que habrá muchas situaciones en las cuales las posibilidades de falsar serán escasas. La construcción de historias se encuentra sometida, entonces, a límites más o menos fuertes dependiendo del respectivo sistema jurídico. En nuestro código procesal penal, por ejemplo, hay reglas de admisibilidad que establecen como punto de partida que cualquier dato puede ser incorporado al proceso excepto aquellos que sean expresamente prohibidos, ${ }^{67}$ como sería el caso de las declaraciones obtenidas de personas sometida a tortura, o bien de la información generada en un proceso de negociación conducente a un acuerdo reparatorio que finalmente fracasó. También es posible que las partes se pongan de acuerdo en cuál será la información de base, como es el caso de las llamadas convenciones probatorias. Para garantizar la calidad de la información se recurre a un procedimiento de acuerdo al cual la contraparte tiene oportunidad de falsarla. El caso más evidente está constituido por la posibilidad de contrainterrogar a testigos y peritos ofrecidos por la parte contraria, con el fin de intentar demostrar que la información por ellos proveída es falsa o cuando menos sesgada. Este mecanismo se explica por cuanto se parte del supuesto que tanto testigos como peritos sienten especial simpatía por los intereses de la parte que los presenta, lo que podría llevarlos a reconstruir sus experiencias desde una perspectiva no totalmente imparcial. ${ }^{68}$

El legislador no considera que siempre tal mecanismo sea suficiente por lo que establece penas a quienes 'faltaren a la verdad' (art. 206, 209 y 210 del código penal). Más aún, se castiga a quienes obstaculicen el esclarecimiento de un hecho o determinación de los responsables mediante la aportación de antecedentes falsos. ${ }^{69}$

Si bien es cierto, el discurso de los abogados no introduce directamente hechos primarios, indudablemente, lo hace de manera indirecta pues serán ellos los que propongan testigos, documentos u otros medios probatorios, como asimismo, formularán las preguntas en el interrogatorio y contrainterrogatorio que orientarán acerca de lo que finalmente se diga. A este nivel, al igual que ocurre con sus clientes los abogados tienen

${ }^{67}$ En el código de procedimiento civil, en cambio, se enumeran los medios de prueba admitidos (art. 341).

${ }^{68}$ En el procedimiento civil las posibilidades de contrainterrogación son mucho más restringidas, por cuanto es el juez quien canaliza la producción de preguntas de las partes (art. 366).

${ }^{69}$ Así también hay un fuerte control de la comunidad científica para la introducción de hechos primarios. Quienes no los respeten serán fuertemente criticados o expulsados de la comunidad. 
una obligación moral y a veces jurídica ${ }^{70}$ de desempeñarse de manera leal, pues no hacerlo podría significar abusar de una posición asimétrica respecto de la contraparte a quien será difícil falsar lo sostenido. Pero, además, los abogados son los principales responsables en el establecimiento de conexiones entre los hechos primarios y el enunciado fáctico último candidato a hacerse calzar con la condición de aplicación de la norma a aplicar (por ejemplo 'Dmitri mató Fiodor, sin que hayan concurrido causales de justificación o exculpación' o 'Dmitri no mató a Fiodor'). Para establecer tales conexiones los abogados recurren al sentido común, teorías científicas, prejuicios, etc., las que suelen presentar bajo la forma de historias. Ya que tanto los jueces como el abogado de la contraparte están en condiciones de detectar posibles fallas en las historias, cualquier exceso o error en que se pueda incurrir no debiera ser especialmente nocivo para el resultado del juicio. En principio, no hay restricciones para la clase de historias que pudieren ser presentadas. Serán los mismos abogados quienes se preocuparán de que sus historias no parezcan fantásticas pues en caso contrario difícilmente podrán ser incorporadas en las sentencias. Como ha sido dicho, en las sentencias se espera que la historia incorporada que conecta (o no) al acusado o demandado con una norma, aparezca como plausible, esto es, que pueda ser considerada como si fuera verdadera en otros ámbitos de nuestra existencia. Así, no sería riesgoso la inexistencia de límites formales, aun a riesgo que se dé lugar a la construcción de historias disparatadas como aquella que habla de que 'por el mar corren las liebres y por el monte las sardinas'. Ya que los jueces tomarán las decisiones sometiéndose a una serie de reglas que delimitan lo que debe y lo que no debe ser aceptado, bastarán las razones prudenciales para que los abogados privilegien sólo aquellas historias que puedan llegar a ser consideradas como si fueran verdaderas y se abstengan de las que aparezcan como disparatadas, pues éstas definitivamente no favorecerán a sus clientes.

\section{BIBLIOGRAFÍA}

Alchourrón, C.E. y Bulygin, E. "Los límites de la lógica y el razonamiento jurídico"/en/ID. Análisis lógico y derecho, Centro de Estudios Constitucionales, Madrid, 1991, p. 303-328. Aristóteles. "Metafísica”, Gredos, Madrid, 1994.

Austin, J. L. “Palabras y acciones. Cómo hacer cosas con palabras”, $1^{\text {a }}$ ed. (Compilación de J. O. Ursom) Paidós, Buenos Aires, 1971.

BARry, B. "Teorías de la justicia”. (1 $1^{a}$ reimp.), Gedisa, Barcelona, 2001.

Bruner, J. "La fábrica de historias". $1^{a}$ ed. Fondo de Cultura Económica de Argentina, Buenos Aires, 2002.

Carnelutti, F., "La prueba civil”. Ediciones Arayú, Buenos Aires, 1955.

Carrió, G., "Lenguaje, interpretación y desacuerdos en el terreno del derecho”/en/Id. Notas sobre derecho y lenguaje. $4^{a}$ ed., Abeledo-Perrot, Buenos Aires, 1990.

${ }^{70}$ En el art. 207 del código penal se sanciona al que a sabiendas presentare testigos, peritos o intérpretes que faltaren a la verdad u otros medios de prueba falsos o adulterados. 
Celano, B., "Decisión judicial y verdad", en Comanducci, P. Análisis y derecho, Fontamara, México D. F., 2004, pp. 137-156.

Chiassoni, P., "Los juegos interpretativos. La interpretación de la ley desde un enfoque griceano", en Navarro, P. y Redondo M. C. La relevancia del derecho, Barcelona, Gedisa, 2002.

Cohen, L. J., "Belief and acceptance", en Mind, vol XCVIII, 1989, pp. 367-389.

Cohen, L. J., "Freedom of proof”, en Twining, W.; Strein A. (eds.) Evidence and Proof. Darmouth, Aldershot, 1992, pp. 3-23.

DAMAŠKa, M., "Las caras de la justicia y el poder del Estado". Editorial Jurídica de Chile, Santiago, 2000.

Ferrajoli, L., "Derecho y razón. Teoría del garantismo penal". 2a ed. Trotta, Valladolid, 1997.

Goldman, A., "Epistemology and cognition”, (5ª reimp.), Harvard University Press, Cambridge, Massachusetts and London, 1986.

Grice, P., "Logic and conversation", en Id. Studies in the way of words. Harvard University Press, Cambridge (Mass.) - London, 1989.

Guastini, R., "Distinguiendo" Gedisa, Barcelona, 1999.

HAACK, S., "Evidencia e investigación. Hacia la reconstrucción en epistemología", Tecnos, Madrid, 1997.

Hacking, I., "The emergence of probability", Cambridge University Press, Cambridge, 1975.

Hanson, N. R., "Patrones de descubrimiento. Investigación de las bases conceptuales de la ciencia". Alianza, Madrid, 1977.

Hart, H.L.A., "El concepto de derecho". 2ª ed. Abeledo-Perrot, Buenos Aires, 1977.

Hawking, S., "El universo en una cáscara de nuez". 99 ed., Crítica/Planeta, Barcelona, mayo 2003.

Kelsen, K., "Teoría pura del derecho". 9a ed., Porrúa, México, 1997.

Kunn, TH., "Objetividad, juicios de valor y elección de teoría”, en Id. La tensión esencial. Estudios selectos sobre la tradición y el cambio en el ámbito de la ciencia. Fondo de Cultura Económica, Madrid, 1993 (2a reimp. en España de la $1^{\mathrm{a}}$ ed.), pp. 344-364.

Nagel, Th., "La última palabra". Gedisa, Barcelona, 2000.

PEÑA. C., "Notas sobre abogados y educación legal. (Borrador para comentarios)", en http://islandia.law.yale.edu/sela/penas.pdf

Popper, K., "Conjeturas y refutaciones. El desarrollo del conocimiento científico". $1^{\mathrm{a}}$ ed. (2 $2^{\text {a }}$ reimp.), Paidós, Barcelona, 1989.

Putnam, H., "El pragmatismo". Gedisa, Barcelona, 1999.

Quine, W. V., "Otherwordly”, en The New York Review of Books, Vol. 25, No 18, 23 nov. 1978.

Rawls, John., "Teoría de la Justicia”. (2 reimp.), Fondo de Cultura Económica, México D. F., 2000.

RESNIK, M., "Elecciones. Una introducción a la teoría de la decisión”. Gedisa, Barcelona, 1998.

Rorty, R., "Does academic freedom have philosophical presuppositions?" /en/ Academe, nov- dec 1994, pp. 52-63.

Rorty, R., "La justicia como lealtad ampliada", en Id. Pragmatismo y política. $1^{a}$ ed., Paidós, Barcelona - Buenos Aires - México, 1998, pp. 105-124.

Ross, ALF., "Sobre el derecho y la justicia", 5 a ed., EUDEBA, Buenos Aires, 1994.

Ruiz-Tagle, P., "Funciones sociales relacionadas con el Derecho" /en/Id. Derecho, Justicia y Libertad. Fontamara, México D.F., 2002, pp. 15-40.

Searle, J., "Actos de habla”. $5^{a}$ ed. Cátedra, Madrid, 2001.

TARSKi, A., "La concepción semántica de la verdad y los fundamentos de la semántica”, en Bunge, M. (ed). Antología semántica, Nueva Visión, Buenos Aires, 1960, pp. 111-157.

Taruffo, M., "Modelli di prova e di procedimento probatorio", en Rivista di Diritto Processuale, $1990 \mathrm{~N}^{\circ} 2$, pp. 420-448. 
Tyler, T., "Why people obey the Law". Yale University Press, New Have - London, 1990.

Ullmann-Margalit, E.; Margalit, A., "Holding true and holding as true", en Synthese, vol 92, año 1992, pp. 167-187.

Wilson, D.; Sperber, D., “Truthfulness and relevance”/en/ Mind Vol 111, july 2002, pp. 583-632.

Wittgenstein. L., "Sobre la certeza”. Gedisa, Barcelona, 2000 (2a reimpresión). Compilado por Anscombe G. E. M. y von Wright, G. H., edición bilingüe. 